\title{
Ritual Artifacts as Memory Stores of Cognitive Habits ${ }^{+}$
}

\author{
Lorenzo Magnani \\ Department of Philosophy and Computational Philosophy Laboratory, University of Pavia, \\ 27100 Pavia, Italy; lmagnani@unipv.it \\ + Conference Morphological, Natural, Analog and Other Unconventional Forms of Computing for Cognition \\ and Intelligence (MORCOM), Berkeley, CA, USA, 2-6 June 2019.
}

Published: 7 May 2020

\begin{abstract}
Ritual artifacts are produced by individuals and/or small groups, left over-there, in the environment, perceivable, sharable, and more or less available. Artifacts of this type can be considered cognitive mediators, insofar as they are collective memory stores of related habits, in the sense that they mediate and make available the story of their origin and the actions related to it, which can be learnt and/or re-activated when needed. Indeed, symbolic habits embedded in rites can also be seen as memory mediators which maximize abducibility, which is the human capacity to guess hypotheses, because they maximize recoverability of already stored cognitive contents. In sum, once suitable representations are externalized in a ritual artifact, they can be sensorially picked up and manipulated to re-internalize them when humans attend the rite: the externalization can be seen as the fruit of the so-called "disembodiment of the mind" as a significant cognitive perspective, able to show some basic features of what I called manipulative abduction, which I will describe in my presentation. When analyzing artifacts and habits in ritual settings, it is important to remember that interesting cases of creative meaning formation are also at play. Actually, we can distinguish two kinds of habits that are at play in rites: (a) a knowledge-based kind of habit, for the analysis of which the concept of "affordance" is useful, which also plays a pivotal role in the justification of the agent's own beliefs; and (b) an ignorance-based kind of habit, which will be proved as necessary for the beginning of thought, and which is at the base of the ampliative abductive reasoning.
\end{abstract}

Keywords: mimetic minds; mimetic bodies; eco-cognitive computationalism; morphology; overcomputationalism

\section{Extended Abstract}

The externalization/disembodiment of mind is a significant cognitive perspective able to unveil some basic features of abduction and creative/hypothetical thinking; its success in explaining the semiotic interplay between internal and external representations (mimetic and creative) is evident. This is also clear at the level of some intellectual issues stressed by the role of artifacts in ritual settings, in which interesting cases of creative meaning formation are also at play. Taking advantage of the concept of manipulative abduction, I have stressed the role of some external artifacts (symbols in ritual tools). I contend that these artifacts, and the habits they originate, can be usefully represented as memory stores and mediators that "mediate", and make available, the story of their origin and the actions related to them, which can be learned and/or re-activated when needed.

An example of ritual artifacts which can be considered "transformers of energy" can be seen in the behavior of some primitive people. They are formed by a process of semiotic delegation of meanings to "mimetic" external natural objects-for example in the ground, which applies energy for final practical purposes through the building of a mimetic representation. To make an example, a ritual artifact can be an analogue of female genitals, which, through a reiterated dance-which 
becomes a habit shared by a collective-in turn mimicking the sexual act, suggests that the hole is in reality a vulva, and refers to the implementation of some agriculture. The artifact makes possible and promotes the related inferential cognitive processes of the rite. Once the representations at play are externalized (representations which are endowed with psychic values), they can be picked up in a sensory way (and so learnt) by other individuals not previously involved in its construction. They can in turn manipulate and reinternalize the meanings semiotically embedded in the artifact.

Primitive minds are not always a "natural home" for thinking towards some targets (for example making agriculture). However, together with the cognitive externalization and the ritual artifact (and the subsequent recapitulations), certain actions can be triggered, actions that otherwise would have been impossible with only the help of the simple available "internal" resources. The whole process actualizes an example of what I have called manipulative abduction. When created for the first time it is a creative social process. However, when meanings are subsequently picked up through the process involving the symbolic artifact and suitably reproduced, it is no longer creative, and becomes a habit, at least from the collective point of view, but it can still be creative from the perspective of individuals' new cognitive achievements and learning. It is possible to infer (abduce) from the ritual artifacts the events and meanings that generated them, and thus the clear and reliable cognitive hypotheses which can in turn trigger related motor responses. They yield information about the past, being equivalent to the story they have undergone. In terms of Gibsonian affordances, we can say that ritual artifacts as memory mediators-as reliable "external anchors"-afford the subject an energy stimuli transduced by sensorial systems, so maximizing abducibility (they maximize "recoverability") and actively providing humans with new, often unexpected, opportunities for both "psychic" and "motor" actions.

I have contended above that the primitive mind is unlikely to be a natural home for complicated concepts, because such concepts do not exist in a definite way in the natural (not artificially manipulated) world. For example, humans always resorted to "external" magical formalities and religious ceremonies, which can release deep emotion and cognitive forces. It is indeed necessary to "disembody" the mind, and after having built a ritual artifact through the hybrid internal/ external interplay, to pick the new meanings up, once they are available over there. The only way is to extend the mind into the material/artifactual world, exploiting the external materials, tools and bodily movements which are suitably enriched through cognitive delegations, to provide semiotic anchors for finding ways of inferring that have no natural home within the mind; that is, for finding ways of thinking that take humans beyond those that natural selection and cultural training could enable us to possess at a certain moment.

The activity of delegation to external objects of cognitive value through the construction of ritual artifacts is certainly semiotic in itself, as the result is the emergence of new intrinsic meanings, expressed by what Jung [1], for example, calls a symbol. It is to be recalled that in these cases, ritual artifacts are the fruit of the hybridization of both internal and external constraints. First of all, this result expresses the "quality" of the cognitive aspects delegated by "minds" to the external materiality, which gives birth to the ritual hybrid interplay. Second, it expresses the particular cognitive "reactions" triggered in other individuals by the ritual materiality at hand (the specific materials, the tools, the shapes made possible by the specific bodies that perform behaviors and actions, etc.).

Jung also nicely stresses the protoepistemic role that can be played by magical artifactual externalizations in creative reasoning, and he is aware that these magical externalizations constitute the ancestors of scientific artifacts, like those-mainly explicit-concerning the discovery of new geometrical properties through external diagrams: Jung says "Through a sustained playful interest in the object, a man may make all sorts of discoveries about it which would otherwise have escaped him. Not for nothing is magic called the 'mother of science' "([1], p. 46). Alchemy, which always provided external symbolism related to "flows of energy", furnishes plenty of examples that support this conviction. Progressively, what possible meaning that can be seen and learnt through artifacts and the related rites can become completely internalized and fixed, so that referral to this externality - and learning from it-is no longer needed. Once internalized, the knowledge and the 
templates of action are already available at the brain level of suitably trained neural networks with their electrical and chemical pathways. When fixed and internalized, they provide an immediate and ready "disposable energy"; for example "We no longer need magical dances to make us 'strong' for whatever we want to do, at least not in ordinary cases" ([1], p. 45).

\section{Reference}

1. Jung, C.G. On psychic energy. In The Collected Works of C. G. Jung, 2nd ed.; Translated by Hull, R.F.C.; Princeton University Press: Princeton, NJ, USA, 1972; Volume 8, pp. 3-66.

() 2020 by the authors. Licensee MDPI, Basel, Switzerland. This article is an open access article distributed under the terms and conditions of the Creative Commons Attribution (CC BY) license (http://creativecommons.org/licenses/by/4.0/). 